\title{
Therapeutic itineraries for patients with cerebrovascular accident: fragmentation of care in a regionalized health network
}

\author{
Márcia Cristina Rodrigues Fausto 1 \\ Estela Márcia Saraiva Campos 2 \\ Patty Fidelis Almeida 3 \\ Maria Guadalupe Medina 4 \\ Ligia Giovanella 5 \\ Aylene Bousquat 6 \\ Angela Carneiro 7 \\ Aline Silva Jerônimo 8 \\ Ítalo Ricardo Santos Aleluia 9 \\ Gabriela Almeida Borges 10 \\ Paulo Henrique dos Santos Mota 11 \\ ${ }^{1}$ Escola Nacional de Saúde Pública. Fundação Oswaldo Cruz. Av. Leopoldo Bulhões, 1480 Sala 319. Rio de Janeiro, RJ, Brasil. CEP: $21.041-210$. \\ E-mail: marciafausto@ensp.fiocruz.br \\ 2 Departamento de Saúde Coletiva. Universidade Federal de Juiz de Fora. Juiz de Fora, MG, Brasil \\ 3 Departamento de Planejamento em Saúde. Instituto de Saúde Coletiva. Universidade Federal Fluminense. Niterói, RJ, Brasil. \\ 4 Universidade Federal da Bahia. Salvador, BA, Brasil. \\ 5 Departamento de Administração de Planejamento de Saúde. Escola Nacional de Saúde Pública. Fundação Oswaldo Cruz. Rio de Janeiro, RJ, Brasil. \\ 6,11 Departamento de Política, Gestão e Saúde. Faculdade de Saúde Pública. Universidade de São Paulo. São Paulo, SP, Brasil. \\ 7,8 Universidade Federal do Vale do São Francisco. Petrolina, PE, Brasil. \\ 9,10 Instituto de Saúde Coletiva. Universidade Federal da Bahia. Salvador, BA, Brasil.
}

\begin{abstract}
Objectives: to analyze the itineraries of patients with cerebrovascular accident (CVA) in the Interstate health region in San Francisco Valley.

Methods: this study uses the qualitative approach through the construction of Therapeutic Itineraries (IT). In the IT mapping the observation was prioritized on the different points and forms to access health service in search of care..

Results: sixteen semi-structured interviews with healthcare users were conducted. There were diverse forms to access and provide services at the Rede Interestadual de Atenção à Saúde do Vale do Médio São Francisco-PEBA (Interstate Healthcare Network Region in the San Francisco Valley), which could be characterized by disorganized and uncoordinated care in the analyzed cases, despite the guarantee of hospital care. The Primary Health Care (APS) teams are present at a care point with most of the patients' itineraries, however, little integration to the regionalized network and they were unable to perform their functions and coordinate the care. It is observed pilgrimage assistance, fragmented care and difficulties in receiving care after post hospitalization which is essential for the patients' rehabilitation.

Conclusions: traces of fragments of the regional health system are important warning signs that points out fragility in PEBA and demonstrate persistent gaps in the public health system to fulfil the responsibility and guarantee individuals' right for health.

Key words Primary health care, Health policies, Health systems, Regionalization
\end{abstract}




\section{Introduction}

Health systems around the world have faced important challenges in the demographic changes and epidemiological characteristics. The population's life expectancy is increasing more and the presence of chronic conditions is also growing within the population, either by aging, for reasons related to lifestyle habits and their social determinants. 1,2 This framework has driven changes in the care systems and the reorientation of their practices to respond health necessities. Many times these necessities are complex, involving multiple approaches and multiprofessional interventions with the participation of different agents and institutions in the process of care. 3

However, the fragmentation in care is a problem in many health systems. It is a limiting factor in offering comprehensive and continuous care, even on the universal basis systems, whose principles are based on the universality and equity to access and have completeness care.

The organization of care in regionalized network is one of the strategies adopted in various Countries to cope with the fragmentation in care. ${ }^{4}$ Although, in Brazil, the proposed constitution of regional networks is prior to the national health reform, this issue gained greater prominence in the beginning of the 21 st century, having as a central point to overcome the high degree of fragmentation in care that hinders the offering of comprehensive and continuous care. Such fragmentation is struck by socioeconomic and geographic inequalities that characterizes national territory, the attribution scope of the State in health, the federative arrangement that involves the three governmental entities - Federal, State, City, - and various agents involved in handling the importance in care. 5

The medical literature has highlighted that in the health systems that adopts the strategy of the regional networks to organize services, the Atenção Primária à Saúde (APS) (Primary Health Care) assumes a central role in coordinating care with emphasis on the related actions either for the prevention of acute situations as to conduct the continuing care directed in handling patients with chronic diseases. ${ }^{6-8}$

The proper and useful care in the assistance process of chronic diseases requires that health services are organized in such a way to offer continuous promotion of care and prevention to their users, besides the interventions to follow, cure and/or rehabilitate with the possibility to access multiple points of the care network, allowing the user to contact different professionals and resources, according to their needs in health. Some studies have emphasized the importance of a strong and articulated APS to set the health system for the expansion to access and have continuity in care, quality in care and the patient's satisfaction. ${ }^{9-12} \mathrm{~A}$ well integrated APS is a necessary condition for this care level to be in a position to coordinate the therapeutic course and allow healthcare users' to have access to services and actions at the location and at a appropriate time 9 and consequently, to encourage positive impacts in the production of health for the population. 10-12

In Brazil, there are a few obstacles to overcome in order to guarantee the integral, coordinated and continuous care, the fragmented scenario characterizes the public health system. 13 Knowing the problems, healthcare users face the paths they experience in the real world is a way to reveal and consider reorientation of policy to ensure their access to health care quality.

The purpose of this article is to analyze the patients' therapeutic itineraries affected by Cerebrovascular Accident (CVA), in the Região Interestadual de Saúde do Médio São Francisco (Interstate Healthcare Network Region in the San Francisco Valley), mapping was given to them to search for care, what influenced, focused and motivated the choices, making it possible to visualize the real networks, patrolled by healthcare users in search of their care.

\section{Methods}

This study is part of the research called "Policy, Planning and Management in Regions and Health Care Networks in Brazil" that analyzes the process of constructing Redes de Atenção à Saúde (RAS) (Healthcare Networks) from the macro-dimensions of policies, structure and organization. ${ }^{14}$ One of the dimensions of the referred study constituted to analyze the APS role as coordinator in care and RAS as the organizer in health regions.

The research field was the Rede Interestadual de Atenção à Saúde do Vale do Médio São Francisco (Rede PEBA) (Interstate Healthcare Network in the San Francisco Valley - PEBA Network), specifically the health macro-regions in Petrolina/PE and Juazeiro/BA. Previously, the formal constitution of the health interstate region was already observed on the intense circulation of healthcare users using the services between Juazeiro and Petrolina regions. In this regard, the formalization goal fulfilled to improve the flow of healthcare users already existed among the regions. 
The PEBA Network was established by the Ministerial Decree number 1,989 on September 23rd, 2008 , appeared with a process to reorganize the health services and actions to ensure access, resolution and comprehensiveness in care. Representatives from Petrolina/PE and Juazeiro/BA, Pernambuco and Bahia States and the Ministry of Health discussed models and forms of organization with a goal to organize the actions and services of medium and high complexity, seeking for completeness health care for the population and the constitution of a macro-region interstate that allows managers to rationalize costs and optimize resources. 15

The PEBA Network is a product of the articulation among managers, health services and actions, above all, urgency and emergency in cities that belong in the IV Macrorregião de Saúde do estado de Pernambuco (Salgueiro, Petrolina and Ouricuri) (IV Health Macro-Region in the Pernambuco State) and the Macrorregião Norte do Estado da Bahia (Paulo Afonso, Juazeiro, and Senhor do Bonfim) (North Macro-Region in Bahia State) have Petrolina and Juazeiro as the main cities. The APS was included in the initial discussion of the regional network, however, subsequently, strategies were not developed for its strengthening.

Situated in the most arid region in the Northeast of Brazil, on the margins of the San Francisco River, on the western part of Pernambuco and the North of Bahia, Petrolina/Juazeiro pole is formed by eight cities in two States; they were distributed in 2013, a population of 686,410 inhabitants.

The total population of the referred PEBA Network is estimated at 2,082,092 inhabitants, 16 distributed in 53 cities, that is, 28 in Bahia State and 25 in Pernambuco State. The IV Health MacroRegion in Pernambuco has a population of 976,474 inhabitants and the North Marco-Region of Bahia, $1,105,618$ inhabitants.

The Rede de Atenção Primária a Saúde (RAPS) (Primary Health Care Network) of IV Macro-Region in Pernambuco is composed of 119 basic health units, 124 APS teams along with Family Health Strategy and 14 teams of the Núcleo de Apoio à Saúde da Familia (The Health Support Nucleus of the Family). The APS Network in the Macro-North of Bahia is composed of 251 basic health units, 297 APS teams in the Family Health Strategy and 27 teams of the Núcleo de Apoio à Saúde da Família. Both regions present a high potential coverage for the population by the APS teams, respectively $98.4 \%$ and $89.3 \%$.

The urgency and emergency network is composed by the Serviço de Atendimento Móvel de
Urgência (SAMU/192) (Mobile Emergency Care Service), which has a predominance of regional coverage in Juazeiro, Paulo Afonso, Senhor do Bonfim and in Petrolina cities. Besides SAMU, an emergency unit (UPA) was implanted and a 24h UPA in Petrolina under State management.

The public hospital network in the region contracted by SUS is composed by medium and large hospitals, as being the entrance door for urgency and emergency to the Hospital Universitário (HU/UNIVASF) (University Hospital) known as the Hospital de Traumas (Trauma Hospital), a reference for urgencies and emergencies care in the Neurology/Neurosurgery (high complexity), Trauma and Orthopedics (high complexity), general surgery, vascular surgery, oral and maxillofacial surgery and medical clinic. In February 2015, this hospital was transferred from the management in Petrolina city for the Empresa Brasileira de Serviços Hospitalares (Brazilian Company of Hospital Services) and it is in the process of structuring equipment and hiring staffs.

The implantation of this interstate network complies in an original case, therefore, it is a pioneer experience in the context of structuring and organizing RAS within SUS. In addition to the Central de Regulação Interestadual de Leitos (CRIL) (Central Interstate Regulation on Hospital Beds), another innovation was the creation of a regional governance area constituted by the Secretaries of Health in Pernambuco and Bahia States, the Secretaries of Petrolina, Salgueiro and Ouricuri cities next to Pernambuco State and Juazeiro, Paulo Afonso and Senhor do Bonfim cities next to Bahia State.

The research activity field in the health region of PEBA in Pernambuco State, Petrolina, Cabrobó and Orocó cities were selected and in Bahia State, Juazeiro, Casa Nova and Remanso cities were also selected. The criteria in each State were: population size (ensured the inclusion of cities with different sizes), number of health establishments (higher and lower); and one of the cities is the regional pole.

Among the possible analysis on the APS role in the health regions and in the RAS, it was decided in this study to emphasize the user's perspective situation in search for health care. For this purpose, the therapeutic itineraries (IT) was taken as a reference approach in order to describe and analyze the individual practices and sociocultural health from the itinerary care performed on individuals and their families in an attempt to solve their health problems, as Gerhardt proposed. 17

The resource to reconstruct the IT is an analyzer 
tool of itinerary search, production and management in health care. Assisting on the recognition of itineraries taken by people in a situation of illness and for their families following, in general, a logic of their own. These itineraries are affected by how the health services produce and provide care, giving them more or less solvable and integrative answers. 18 The IT structure requires, therefore, the recognition of various conditions that influence and interfere in search for care, from the perspective of healthcare users' networks in health areas.

For the IT to work, it is necessary to choose a tracer, as Kessner et al., ${ }^{19}$ proposed, that departs from the premises that some health problems can be particularly useful for the analysis of providing services and the interaction among providers, healthcare users and the society. The selected tracer for the present study was the Cerebrovascular Accident (CVA) resulting from a high blood pressure (HAS). CVA is a severe disease related, in most cases, complications of hypertension whose main locus of care should be the APS and integrating to the current Brazilian list of hospitalizations for sensitive conditions in primary care. 20 There are protocols defining CVA, including effective actions in the APS framework in promoting, preventing and controlling the disease. In addition, in the medical literature are highlighted the importance of articulating and coordinating actions among the diverse points of care and the various health professionals involved in the care of healthcare users with CVA. 21

The study uses a qualitative approach considering the experience of patients affected by the event of the chosen tracer. It was used as a technique for data collecting the structured interview guided by a script, which served to facilitate the introduction of questions and to deepen the level of information. ${ }^{22}$

To identify the interviewees' potential, forms for Hospital Admission Authorization (Autorização de internação hospitalar -AIH) were selected in the Hospital Information System of SUS (Sistema de Informação Hospitalar do SUS - SIH-SUS), to be hospitalized, the primary diagnosis was AVE and the secondary diagnosis HAS was of hospitalized patients at the Federal University Hospital of San Francisco Valley, a reference area for these cases in this region. AIH were selected regarding hospitalizations with hospital discharge occurring up to six months prior to complete the interviews, which took place in July, 2016. The information was registered as: the patient's age, sex, city of residence, home address, the city where the occurrence was and hospitalization duration. The healthcare users were identified and selected; a phone contact was made to schedule the interview, which was held at the user's home with his/her family. The interviews were recorded, transcribed and then reconstructed in a narrative form.

In the therapeutic itineraries mapping was prioritized on the observation of the patients and their families itineraries and behavior, identifying the different points and forms to access health services in search for CVA care.

The qualitative analysis comprehended the transcriptions of the interviews, depth material reading, the table of findings, writing of a narrative summary and the IT elaboration, in order to provide an understanding in a temporal perspective. The saturation was obtained by identifying and the repetition of points accessed for care by these healthcare users.

The study was approved by the Ethics Committee of the Faculdade de Medicina da Universidade de São Paulo, process number 071/15, and in accordance with the norm of the National Health Council 466/12.

\section{Results}

16 healthcare users residing in the cities of Casa Nova/BA, Juazeiro/BA, Petrolina/PE and Remanso/BA were interviewed. The interviewees' age ranged from 36 to 82 years, $9(56 \%)$ were males and 7 (44\%) were females. Among them, 11 (69\%) lived in urban areas and $5(31 \%)$ in rural areas of the cities. The hospitalization period ranged between one and 30 days.

The IT analysis evidenced the experiences of patients, family members and other members of the support network to identify the itineraries in search of care in patients affected by a disease in acute situation, admitted in the Hospital Geral de Traumas da Universidade Federal do Vale do São Francisco (General Hospital of Traumas at the Federal University of San Francisco Valley). From the 16 itineraries studied, they were analyzed as: the APS and the care received before the AVE episode; the path taken at the moment of the urgency; hospitalization; the care received after hospital discharge; the role of the family in care management; and the mix public and private access to health services.

\section{The APS and the care before the occurrence of CVA}

Different patterns of using APS were identified in the period that preceded the episode of CVA. In 12 
itineraries, some types of follow up were noticed as, regular or irregular, with diagnosis and HAS by the teams. Four healthcare users did not report any type of care by the APS teams, but one of them had a private health plan. In one of these cases, although, the HAS follow up occurred preferentially by a health plan with access for the specialists, the UBS also seemed to be the place to follow up on the pathology, in an irregular form, and also the dispensation of medications. Seven cases were identified as a regular follow up on the pre and post AVE by the APS team.

It is noteworthy that the APS teams are present, in some way, as a point of care in most of the patients' itineraries. However, as we are dealing with healthcare users with a chronic disease, only the regular follow up with the coordination of care could decrease the risks that CVA caused. In this regard, the UBS is not configured as a point of effective care in these healthcare users' follow ups, by observing the presence of other specialized services in a fragmented form.

The report was recurrent on the low adherence to HAS treatment, which summarized pharmacological treatment. Practices in health education are aimed to prevent risks and promote health, which were not identified in any of the interviews. The guidance about the warning signs of an CVA was also not identified.

A strong relation with the APS service was evidenced by dispensing medications, even in an irregular form with problems supplying this could imply a direct purchase on the part of the medication prescribed.

It was perceived the difficulty for the APS to follow up cases of residents in rural areas, probably due to the territorial dispersion and the various demands to be attended daily by the teams, which produces a definition of priorities based on more pressure in care than in the users' health needs.

\section{The path taken at the moment of the urgency}

In five cases, the UBS was the first search when the first symptoms of CVA appeared and, in some cases with verbal orientation to search for a hospital. In six cases, the access for hospitalization occurred by SAMU or the ambulance in the city and in nine cases the access was by their own transport, relatives or neighbors. The SAMU appeared as a resource driven by family members in situation of urgency, besides, the use of their own transportation, in most cases, regardless to the type of IT. In the ITs studied, some cases were observed, in which, the time to be hospitalization would occur, but was not appropriated, as for, there were long waiting hours in the emergency room.

It was possible to identify patients and their families' itineraries of coming and going, at the moment of an CVA episode looking for care at the health services in the region. The healthcare management by family members generated pilgrimage cases in search for urgency care. The previous searches for UPAs, Regional Hospitals, clinics and hospitals affiliated with SUS or at private hospitals occurred both in the region of Petrolina and Juazeiro, regardless of the location of residence is in the rural or urban area. Among the healthcare users in Petrolina region, the itinerary of care took place in UBS, UPA and University Hospital of Trauma. In the case of healthcare users in Juazeiro, Casa Nova and Remanso cities, the search for care occurred by itineraries among UBS, Regional Hospital, PróMatre Hospital (linked to SUS) and UNIMED (private network).

\section{The hospitalization}

The University Hospital was the reference place for all the interviewees before the CVA symptoms. It is noteworthy that there had been no reports of refusals to be hospitalized and nor barriers arose from the circulation of healthcare users from different Cities and States.

The ITs show different patterns in relation to quality and the opportunity to receive treatment at this service. There are reports from two healthcare users who stayed 24 hours in the emergency room and another one reported staying 30 days in the hospital. Only three of the sixteen healthcare users reported having a consultation with a neurologist during hospitalization. The other four have reported that there was no contact with a neurologist during hospitalization, three could not inform and eight said they had a consultation with this professional after hospital discharge. One interviewee reported having consultations with a neurologist during and after hospitalization. Regarding to tomography, six of the sixteen healthcare users reported in performing the examination during the hospitalization period, and one of them mentioned that this examination was performed 2 days after the hospitalization. Another healthcare user mentioned that the tomography was performed after the hospital discharge, the exam that was paid by the same patient, through a direct disbursement. Only one healthcare user, had a private health plan, passed by the Hospital and did not stay to receive treatment for CVA, the patient 
was removed to a private hospital by his wife in their own transportation, after hours waiting in the hallway, without any care assistance. The interviews showed that even healthcare users who have a health plan build itineraries that connect the private network services to the public network.

Besides the results observed, it is plausible to assume that in addition to the insufficient offering, there are serious problems of quality in hospital care provided to the healthcare users with CVA that were interviewed. Although, for some of them, they cannot be excluded of the bias occurrence in respect to the procedures that occurred during hospitalization.

\section{The care received after hospital discharge}

There was a lack of adequate guidance on the hospital discharge, the reference to hospital service to the APS service was not tonic and, in a few cases where this occurred it was verbally. The report on hospital discharge was not always available for the patient. In both cases the patients had tests to perform and return to the outpatient ambulatory but did not know what the papers meant when they were given by the hospital staff.

Although, there were indications to be followed up by a neurologist, cardiologist and a physiotherapy treatment, in most cases, the healthcare user does not have access to such services, probably because these indications are performed by the hospital to constitute more like a "recommendation" than a reference with guaranteed access.

In the cases analyzed in Juazeiro three patients were not taking medications, because they were waiting to be appointed by the APS service the exams requested and the consultation with the neurologist. In all the CVA cases, in the two macroregions, the high level professional of the APS team did not conduct a home visit, leaving the patients lying in bed being followed up only by the ACS.

Living in rural areas has been far more difficult to be followed up by the APS. In two ITs, the follow up by the APS teams begin after hospital discharge. In three cases, it was identified regular follow ups by the APS on pre and post hospitalization. It should be noted that, even in these cases, the teams are not constituted as healthcare coordinators, without establishing any kind of contact with other levels and services needed by the patient.

Difficulties to access rehabilitation resources were mentioned by all the healthcare users interviewed. For families who could afford to own resources (4) it was possible for the patient with
CVA to access care for physical therapy, through direct disbursement, often with members of the family, they share the expenses. Families of healthcare users living in a rural area (2) reported difficulties with the transportation to go to the hospital for regular sessions of physical therapy, given the reason because of the distance between the service and the residence of the patient.

Among the ITs analyzed they were recurrent in the interviewees speech, the use of medicinal plants as a therapeutic resource in the treatment after the AVE episode. This is part of the local culture to use the so-called "nine mixtures" (composition: sunflowers, imbiriba, Japanese star anise, nutmeg, pichuri, mustard, the smell of umburana, coriander and sesame seeds) for the prevention and recovery of AVE. However there are no studies on the effect of these substances.

\section{The role of the family in care management}

It should be emphasized that in all ITs could be shown that the family was constituted as the main support network, being responsible to access the urgency services, as well as the disbursement to do the tests and to buy some medications, even presenting financial difficulties due to their socioeconomic condition. Most of the families were composed by many family members, several are healthcare users affected by numerous of children, up to eight children. There was also an important presence of the extended family: nephews and nieces, cousins, uncles and aunts.

The family has a strong care management there is a person who decides which service to go to in the network, and between the coming and going to urgency, emergency hospital and referral hospitals units, seek the necessary care for the family. In some ITs, the support network showed to be expanded besides the family, with the presence of friends and relatives trying to make it easier to access SAMU, to get a vacancy at the hospital, as well as the dispensation of medications. In addition to access SUS services by the means of formal flows, family members also make use of personal relationships to facilitate the use of SAMU, to achieve vacancy to be hospitalized and have rehabilitation and even to use a private car to go to physiotherapy sessions.

\section{Mix public and private access for health services}

The use of direct disbursement and articulation with the private services were, therefore, present elements 
when analyzing the itineraries. Considering the use of public and private health services, there are three types of interactions:

a) Exclusively in public services: identify based on the experience of healthcare users with very low economic status. This type of IT, there was no presence of the private or public sector linked to and no direct disbursement to family members by total lack of financial resources. In these cases, it excelled the non-access to necessary resources for care.

b) In public services with a strong presence of family intervention to guarantee the care: in these cases, the insufficient network was, in part, supplied in the private network through the purchase of services (consultations, exams) and medications for direct disbursement. This type of IT was observed, including even in healthcare users who belong to poor families. These ITs emerged the greatest possibility to access needed resources for care especially in the commitment of the families in search for these resources. However, the non-access was present.

c) In public and private services: these ITs were verified from the experience of the healthcare users who had a health plan and to have access of treatment for families who built itineraries that connect the private network services to the public network. These ITs predominated the possibilities to access necessary resources for care.

\section{Discussion}

This study showed a high degree of care fragmentation to people with AVE. Not only the relations and flows among the services but presented weaknesses and discontinuities, as to access and care in each point of the system, which showed insufficiency and non-solving, by expressing much evident gaps that persist in the public health system in terms of fulfillment of sanitary responsibility and the guarantee the individuals' right for health.

In regards to the APS, even though healthcare users, for the most part, have been accompanied by professionals at the basic network, the irregularity in the service and in the supply of medications, besides the difficulties to have access - especially for those living in rural areas - this results in poor quality in the care provided with the effects that reflect in a permanent way in the individuals' lives. For these, the advent of CVA not only aggravated the health situation but as, perversely, putting them in a greater helplessness position, once the institution in the region does not offer as for the APS try to establish solid connections with the hospital and specialized care, so that the public health system ensures the care for essential services, besides hospitalization, such as consultation in neurology, cardiology and respiratory therapy. The APS is part of the network that integrates the region, however, it does not articulate to specialized care (outpatient ambulatory and hospitalized inpatient) within the regionalized interstate network, characterizing a fragmented network. The APS, in this case, was not effective in their abilities to allow access and coordinate care, neither in the development of rehabilitation actions that promote social reintegration of healthcare users in their everyday life. It is worth mentioning that Petrolina has been the scene of major investment in the APS network, which can have a positive impact in the near future.

In the course of assistance in the cases analyzed draws attention to: the absence of a report on the participation of healthcare users in preventive or educational activities, offered at the UBS; the nonregularity home visits occurred prior to or after an CVA episode; home care for healthcare users in bed correspond to their specific needs and does not imply for the continuity of care; and the nonoccurrence visit of the APS team to the healthcare user during the hospitalization period, in cases which there were already a follow up on the patient by the APS before the CVA episode.

Left to their own devices, the healthcare users use other resources to solve their problems and their success will be directly related to the capacity and the dimension of their social support network (especially family and friends) and their own economic situation (financially) and social (expressed with their friendship and with others a symbolic exchange), as some studies have indicated. ${ }^{23,24}$ It is through these resources, outside of the public health network, that the healthcare users pass the obstacles to have access to specialized care, the purchase of medications, and even access care (SAMU, consultation with specialists and vacancy in hospitals, for example) in the public system. The frequent use of phytotherapic reflects much in the Northeast culture and is common in other locations. 25

If the APS services are not configured as a regular source of care and do not fulfill the role in the system and coordinate care, on the other hand, the assistance in the specialized care and hospital area have also proven to be largely inadequate in the inter-federative region studied, although there are important efforts of improvement and expansion on behalf of the managers.

There were no evident mechanisms or strategies 
that promote the articulation of the service and professionals (the APS and specialists) to integrate actions and continuous care for the healthcare user post-CVA. It was not noticeable the reference and the counter-reference practice, nor was evidenced the well established and regulated regional flow to guarantee the appropriate and integrated access to the network. The analysis of ITs points out that health actions, either in the APS space or specialized care, professionals and teams provide care individually and without any type of link. Therefore, it is apparent that the access, appropriate or not, to different services is more dependent on the persistent search and the level of understanding the processes by healthcare user and his/her family, as a matter of fact, the structuring and organization of the health services.

The efforts of the interstate network organization still has guaranteed, in some way, access to medical transportation services and hospitalization, with no refusals for hospitalization and barriers arising from the circulation of healthcare users from different Cities and States, were insufficient to guarantee a continued care. The findings in this study show the important fragmentation and gaps in care itineraries of healthcare users affected by CVA. The forms to have access and the offering of services in the PEBA interstate region is still characterized by an unorganized and uncoordinated care, showing organizational weaknesses in health regionalized networks linked to the Country and, theoretically, in a construction phase in the region studied. This research confirms findings of previous studies the very own regionalization process, which marks the low of coordination and planning actions, especially from the APS, $26-28$ as well as other more recent studies that test the fragility of the articulation between the levels of care in regional networks, a recognized fact by managers themselves in another health region in São Paulo State. 29

It should be noted that the presence of the University Hospital in the region is a critical component for the patients' care who were affected by AVE. With all the obstacles in care present in the therapeutic itineraries analyzed in this study, the University Hospital of Traumas has allowed the access of the interviewed healthcare users who arrive at the emergency department, through formal or informal ways, from the two macro-regions that link the interstate health region.

In the case of PEBA network, a resource set of the APS do not take part of the interstate network design. Although it is present with a high population coverage in the territories that make up the region, not being part of the regionalized network design does not makes it possible to act in the central point, the entrance door to resolute and coordinate care in the network. This is not a peculiarity of the region studied, but derives from the decentralization model assuming in the national health policy that must be put into practice in an environment where the federal entities have a high degree of decision-making autonomy. If on one hand, this model has promoted the expansion of access to APS services in different Brazilian cities, then on the other hand, the fragility of regional space and the low inclusion of APS as a matter for federative intergovernmental pacts put enormous challenges to articulate, it is so necessary to confront the main problems of health that characterize the epidemiological profile of the population.

The itineraries analyzed in this study, corroborate what for decades has been discussing in Brazil regarding the formation of regionalized networks for health care. And to install the capacity does not guarantee that the regionalized health network will constitute. Elements such as the profile on care, service integration, economy scale, regulating the patients' access to different levels of care or the allocation of health services resources, for equity and efficiency reasons are elements to plan and organize the regionalized network. 4,30

The difficult effects to access multiple points of care with absolute insufficient coordination in care are severe and perverse for healthcare users affected by CVA. CVA is a disruptive event in the lives of patients and their families and caregivers. In addition to the adequate care in the acute event, the actions of physical rehabilitation and psychological and social support are essential for the quality of life. ${ }^{21}$ It is worth noting that the integrated work of the network, the clear knowledge of the warning signs, a working network for urgencies and emergencies, imaging exams available in time and the use of thrombolytic when indicated, all of this can drastically change the future of these families.

This study presents limitations that need to be acknowledged. This is a qualitative study in a region, which seeks to deepen into the theme within the specific limits of context. The discussions from the therapeutic itineraries were to understand in depth how the process to search for healthcare by different subjects and social groups is the most significant point to justify the choice of the method. At the same time, the construction of ITs understood the itineraries for care were marked by subjective issues. It is necessary to admit that the reports that served as the base for this study are marked by culture, values, 
experiences, historical conditions and social, to the extent that maintains a relation in the way people behave in search for health services and in relation to diseases.

One of the questions that can be raised as to the ownership of this study is to verify the effectiveness of the care network concerns the methodological option to work with therapeutic itineraries of patients with CVA. This event is an unwanted consequence and it is known, a complication related to failures in accompanying patients with hypertension, the study highlights, precisely, the deficiencies of the system, not being able to reveal cases of success, since these last ones only rarely are related to this type of outcome. Mentioned in another way, an effective follow up and a timely access to all the services of the health system reduces the

\section{References}

1. Schimidt MI, Duncan BB, Silva GA, Menezes AM, Monteiro CA, Barreto SM, Chor D, Menezes PR. Doenças crônicas não transmissíveis no Brasil: carga e desafios atuais. The Lancet. 2011; 377 (9781): 1949-61.

2. Alves RFS, Faerstein E. Educational inequalities in hypertension: complex patterns in intersections with gender and race in Brazil. International Journal for Equity in Health. 2016; 15: 146

3. Malta DC, Merhy EE. O percurso da linha de cuidado sob a perspectiva das doenças crônicas não transmissíveis. Interface Comun Saúde Educ. 2010; 14 (34): 593-606.

4. Kuschnir R, Chorny A. Redes de atenção à saúde: contextualizando o debate. Ciênc Saúde Coletiva. 2010; 15 (5): 2307-16.

5. Albuquerque MV, Viana AL, Lima LD, Ferreira MP, Fusaro ER; Iozzi FL. Desigualdades regionais na saúde: mudanças observadas no Brasil de 2000 a 2016. Ciênc Saúde Coletiva. 2017; 22 (4): 1055-64.

6. Peroni FM. Tecendo redes: itinerários terapêuticos de pacientes com câncer na macrorregião de Campinas [tese] São Paulo: Faculdade de Ciências Médicas da Universidade Estadual de Campinas; 2013.

7. Hudon C, Chouinard MC, Diadiou F, Lambert M, Bouliane D. Case management in primary care for frequent users of health care services with chronic diseases: a qualitative study of patient and family experience. Ann Fam Med. 2015; 13 (6): 523-8.

8. Lamothe L, Sylvain C, Sit V. Multimorbidity and primary care: Emergence of new forms of network organization. Sante Publique. 2015; S1 (HS): 129-35.

9. Tarrant C, Windridge K, Baker R, Freeman G, Boulton M. 'Falling through gaps': primary care patients' accounts of breakdowns in experienced continuity of care. Family practice. $2015 ; 32$ (1): 82-7.

10. Hansen J, Groenewegen PP, Boerma WG, Kringos DS. likelihood of an CVA occurrence, as well as its complications, however, does not mean that in some time these cases can occur. Thus, the studied cases could be representing extemporaneous situations, an exception to the rule, not mentioning correctly the effort to organize the system in the region.

Nevertheless, this study shows that the tenuous ties between the healthcare users and the services remain in its whole course of therapeutic itineraries. The persistence traces of deep fragmentation in the health regional system, here it is evident, that the warning signs are important for the management to undertake strategies to improve the magnitude and quality of offering and network integration, and thus comply with the sanitary responsibility of ensuring the universal right to have access to quality health services.
Living In A Country With A Strong Primary Care System Is Beneficial To People With Chronic Conditions. Health affairs. 2015; 34 (9): 1531-7.

11. Tricco AC, Antony J, Ivers NM, Ashoor NM, Khan PA, Blondal E, Ghassemi M, MacDonald H, Chen MH, Ezer LK, Straus SE. Effectiveness of quality improvement strategies for coordination of care to reduce use of health care services: a systematic review and meta-analysis. CMAJ. 2014; 186 (15): E568-78.

12. Boerma W. Coordination and integration in European primary care. In: Saltman DC, Rico A, Boerma W, eds. Primary care in the driver's seat? Berkshire: University Press; 2007: 3-21.

13. Paim JS, Travassos C, Almeida C, Bahia L, Macinko J. The Brazilian health system: history, advances, and challenges. Lancet. 2011; 377 (9779): 1778-97.

14. Viana ALD, Bousquat A, Ferreira MP, Cutrim MAB, Uchimura LYT, Fusaro E et al. Região e Redes: abordagem multidimensional e multinível para análise do processo de regionalização da saúde no Brasil. Rev Bras Saúde Matern Infant. 2017; 17 (Supl. 1).

15. Rede Interestadual. Projeto de Implementação da Rede Interestadual de Atenção à Saúde do Médio São Francisco (Documento para discussão no II Fórum da Macrorregião); 2009. 137p.

16. IBGE. Instituto Brasileiro de Geografia e Estatística. Estimativas de população de Pernambuco para 2015. Disponível em: < http://tabnet.datasus.gov.br/cgi/tabcgi. exe?ibge/cnv/poptba.def $>$.

17. Gerhardt TE. Itinerários terapêuticos em situações de pobreza: diversidade e pluralidade. Cad. Saúde Pública. 2006; 22(11): 2449-63.

18. Bellato R, Araújo LFS, Mufato LF, Musquim CA. Mediação e mediadores nos itinerários terapêuticos de pessoas e famílias em Mato Grosso. In: Pinheiro R, Martin 
PH, orgs. Usuário, redes sociais e integralidade em saúde. Rio de Janeiro: Cepesc-IMS/UERJ; 2011. p. 177-83.

19. Kessner E, Kalk CY, Singer J. Assessing health quality. The case for tracers. The New England Journal of Medicine 1973; 2888(1):1888-1894.

20. Alfradique ME, Bonolo PF, Dourado I, Lima-Costa MF, Macinko J, Mendonça CS, Oliveira VB, Sampaio LFR, De Simoni $C$, Turci MA. Internações por condições sensíveis à atenção primária: a construção da lista brasileira como ferramenta para medir o desempenho do sistema de saúde (Projeto ICSAP - Brasil). Cad Saúde Pública. 2009; 25: 1337-49.

21. Lou S, Carstensen K, Jorgensen CR, Nielsen CP. Stroke patients' and informal carers' experiences with life after stroke: an overview of qualitative systematic reviews. Disabil Rehabil. 2016; 39 (3): 301-13.

22. Minayo, Maria Cecília de Souza (org.). Pesquisa social: teoria, método e criatividade. 29. ed. Petrópolis, RJ: Vozes, 2010. (Coleção temas sociais)

23. Medina MG. O contexto local, a organização da atenção primária e a implementação de redes integradas de atenção à saúde: resultados da avaliação de dois estudos de caso [tese]. Salvador: Instituto de Saúde Coletiva da Universidade Federal da Bahia; 2006.

24. Pineault R, Tousignant $P$, Roberge $D$, Lamarche $P$, Reinharz D, Larouche D, Beaulne G, Lesage D. Research collective on the organization of primary care services in Québec. Québec: Diréction de santé publique. Agence de développement de résaux locaux [Detailed Report]; 2005.
25. Oliveira DMS, Lucena EMP. O uso de plantas medicinais por moradores de Quixadá-Ceará. Rev Bras Plantas Med. 2015; 17 (3): 407-412

26. Aleluia IRS, Medina MG, Almeida PF, Vilasbôas ALQ. Coordenação do cuidado na atenção primária à saúde: estudo avaliativo em município sede de macrorregião do nordeste brasileiro. Ciênc Saúde Coletiva. 2017; 22 (6): 1845-56.

27. Almeida PF, Marin J, Casotti E. Estratégias para consolidação da coordenação do cuidado pela Atenção Básica. Trab. Educ. Saúde. 2017; 15 (2): 373-98.

28. Kitzman P, Hudson K, Sylvia V, Feltner F, Lovins J. Care Coordination for Community Transitions for Individuals Post-stroke Returning to Low-Resource Rural Communities. J Comm Health. 2017; 42 (3): 565-72.

29. Bousquat A, Giovanella L, Campos EMS, Almeida PF, Martins CL, Mota PHS, Mendonça MHM, Medina MG, Viana ALD, Fausto MCR, Paula DB. Atenção primária à saúde e coordenação do cuidado nas regiões de saúde: perspectiva de gestores e usuários. Ciênc Saúde Coletiva. 2017; 22 (4): 1141-54.

30. Kuschnir R. Organizando as Redes de Atenção à Saúde: perfis assistenciais, articulação entre níveis e organização das linhas de cuidado. In: Kuschnir R, Fausto MCR, orgs. Gestão de Redes de Atenção à Saúde. Rio de Janeiro: EAD/ENSP; 2014.

Received on June 27, 2017

Final version presented on August 29, 2017

Approved on September 13, 2017 